Nunt. Antiquus, Belo Horizonte, v. 14, n. 2, p. 61-90, 2018

\title{
A arkhé da poesia e do drama na Poética de Aristóteles
}

\section{The arkhế of Poetry and Drama in Aristotle's Poetics}

\author{
Rafael Guimarães Tavares da Silva \\ Universidade Federal de Minas Gerais (UFMG), Belo Horizonte, Minas Gerais / Brasil \\ CAPES \\ gts.rafa@hotmail.com
}

Resumo: A Poética de Aristóteles é uma obra fundamental para a compreensão do desenvolvimento da poesia e da filosofia entre os herdeiros da tradição helênica, constituindo um momento especialmente fecundo da reflexão filosófica sobre a arte poética. Após situarmos o contexto intelectual de sua produção, pretendemos avançar uma série de considerações sobre a importância assumida pela noção de arkhế("origem; princípio; poder") da poesia e do drama no interior da argumentação aristotélica a fim de compreendermos as razões que podem tê-lo levado a se contrapor a alguns dos mais radicais posicionamentos presentes na obra de Platão no tocante à poesia. Para isso, efetuaremos uma leitura cerrada do texto da Poética, enriquecendo-a com uma abordagem intertextual e guarnecida por estudos especializados, e proporemos ainda interpretações pontuais de trechos especialmente obscuros (como é o caso da célebre passagem sobre a origem ditirâmbica da tragédia).

Palavras-chave: poética antiga; filosofia antiga; drama antigo; Aristóteles; Poética.

Abstract: Aristotle's Poetics is a fundamental work to understand the development of poetry and philosophy among the heirs of the Hellenic tradition, constituting a particularly fruitful moment of philosophical reflection on poetic art. After situating the intellectual context of its production, we intend to advance a series of considerations on the importance assumed by the notion of arkhế ("origin; principle; power") of poetry and drama within the Aristotelian argumentation in order to understand the reasons that may have led him to oppose some of the most radical Platonic positions on poetry. In order to achieve this objective we will realize a close reading of the Poetics, enriched with an intertextual approach to the text and using specialized studies in this movement. We will also propose specific interpretations of especially obscure passages, such as the famous passage about the dithyrambic origin of tragedy.

Keywords: ancient poetics; ancient philosophy; ancient drama; Aristotle; Poetics. 
Principiemos com uma passagem célebre do prefácio aos Fundamentos da filosofia do direito de Hegel, onde o autor reflete sobre a relação entre o real e o ideal:

Sobre o ensinar como o mundo deve ser, para falar ainda uma palavra, a filosofia inevitavelmente sempre chega tarde demais. Enquanto pensamento do mundo, ela somente aparece no tempo, depois que a efetividade completou seu processo de formação e se concluiu. Aquilo que o conceito ensina mostra a história necessariamente do mesmo modo: que somente na maturidade da efetividade aparece o ideal frente ao real e edifica, para si, esse mesmo mundo, apreendido em sua substância na figura de um reino intelectual. Quando a filosofia pinta seu cinza sobre cinza, então uma forma da vida se tornou velha e, com cinza sobre cinza, ela não se deixa rejuvenescer, mas apenas conhecer; a coruja de Minerva somente começa seu voo com a irrupção do crepúsculo. (HEGEL, 2010 [1967], p. 44). ${ }^{1}$

Toda obra antiga que aspire à função de arte poética (no sentido clássico) é, de certo modo, a coruja de Hegel: desperta apenas quando o esplendor solar do bosque que ela então encara, com o crepúsculo do dia, está chegando ao fim. Mas isso não indica que sua função se restrinja a descrever o que passou. Muito antes pelo contrário, observando o passado e posicionando-se prescritivamente com relação a ele, toda poética clássica orienta tanto mais a recepção futura e a produção dos poetas por vir quanto mais autoridade ela própria lhes inspira. Os olhos da coruja - que esquadrinham o estado de coisas no crepúsculo do bosque e descobrem muito daquilo que acontecera antes - determinam, até certo ponto, a possibilidade de movimento às criaturas da noite, além de exercer uma influência determinante sobre muito do que ainda há de acontecer no início da próxima aurora.

\footnotetext{
${ }^{1}$ Todas as traduções de textos em língua estrangeira para o português são de nossa autoria, a menos que se explicite em nota o nome de quem o traduziu. No presente caso, tradução de Paulo Meneses et al.
} 
Acredito não precisar evocar os testemunhos de Peter Szondi (2004) e Roberto Machado (2006) para indicar a importância fundamental que Aristóteles teve para o desenvolvimento de uma poética moderna, a partir do "redescobrimento" da dimensão poética de sua obra no Renascimento, mas sobretudo a partir do debate que franceses e alemães mantiveram acerca da tragédia desde o séc. XVII até o séc. XIX. A proposta aqui é entender de que forma esse filósofo refletindo sobre a arte poética em seu próprio contexto epistemológico - desenvolveu uma teoria que dá conta dos efeitos e especificidades da poesia, articulando essa questão à origem do fenômeno poético e, mais especificamente, do dramático. Trata-se, portanto, de uma obra filosófica dotada de uma dimensão histórica e teórica de viés descritivo, embora também seja prescritiva: sua influência se faz sentir não apenas sobre a produção de futuros poetas e tragediógrafos, mas até mesmo sobre uma corrente filosófica que viria a conceber a obra poética como um objeto de estudo digno em suas próprias especificidades. Creio que uma melhor compreensão das estratégias adotadas por Aristóteles nessa obra fundacional de um tipo de abordagem tão determinante para nossa tradição estético-filosófica possa revelar uma série de desdobramentos pouco conhecidos acerca de nós mesmos. Antes, contudo, de entrarmos em sua Poética, alguns esclarecimentos preliminares.

Aristóteles produz seus tratados filosóficos em diálogo e diferença com relação a muito daquilo que seu mestre, Platão, havia desenvolvido em sua vida e obra. Essa posição ambivalente deve ser sempre levada em conta por quem queira compreender as proposições aristotélicas, na medida em que elas se inserem numa relação dialógica e diferencial complexa: a fim de que suas considerações sejam analisadas de maneira fecunda pelo intérprete, é preciso ter uma consciência aguda desse aspecto relacional.

Nesse sentido, um primeiro ponto a ser observado é que a obra supérstite de Aristóteles - ao contrário da de Platão - emprega de modo praticamente exclusivo o gênero tratadístico e abandona a composição de diálogos. Por mais que isso possa se dever aos acasos da transmissão das obras, ao que tudo indica, o estagirita teria composto apenas alguns diálogos em sua juventude (como o Perì poiêtồn [Sobre os poetas], por 
exemplo), embora essas obras tenham se perdido e existam apenas em fragmentos. Além disso, não é de se ignorar que as obras tradicionalmente consideradas tardias de Platão - como o Timeu e as Leis - já apresentavam uma série de características mais próprias do que viria a ser o tratado filosófico ao modo aristotélico do que dos diálogos socráticos: longas exposições de temas específicos; abordagens sistemáticas desses temas; certa impessoalidade em sua apresentação etc. Em que pesem essas aproximações entre a obra do final da vida de Platão e as primeiras obras (perdidas) de Aristóteles, é de se destacar que as diferenças no meio empregado para abordar suas questões filosóficas acarretam mudanças consideráveis no modo de apresentação e tratamento das mesmas. Como se há de sugerir ainda, essas diferenças são refletidas também na relação estabelecida entre o discurso filosófico, tal como proposto por Aristóteles, e outros gêneros do discurso vigentes em Atenas e no mundo helênico, como a poesia e a retórica. ${ }^{2}$

Aristóteles devota uma obra inteiramente à arte poética - ainda que ela pareça ser composta por uma série de notas pouco sistemáticas, tomadas para a realização de um curso sobre o tema - e, em sua parte inicial, desenvolve tanto uma teoria sobre a origem da poesia quanto uma teoria sobre a origem do drama. Infelizmente, ainda não é possível precisar a data de composição da Poética - a fim de se estipular com que obras e acontecimentos históricos ela poderia estar mais em consonância -, sendo necessário imaginar um ou mais momentos entre 367 a.C., ano da chegada de Aristóteles a Atenas, e 322 a.C., ano de sua morte.

Tal como sugerido pelo estudo de Depew (2007, p. 132), a Poética desenvolve-se segundo um modo analítico de tratamento do fenômeno poético, oferecendo: i) uma definição (horismós); ii) uma explicação de sua causa (ho dêlồn dià tí éstin); iii) e uma demonstração conclusiva de sua essência (tềs tồ tí estin apodeixeōs sympérasma). Essas são as diretrizes de definição traçadas em Analíticos posteriores 2.10 (93b2894a12) e seguidas em inúmeras discussões biológicas de Aristóteles, sendo ainda responsáveis pelo arranjo da Poética.

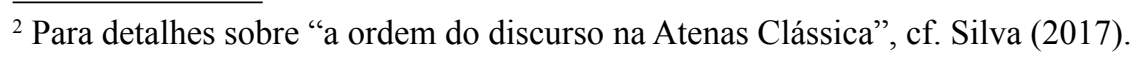


Assim como a História dos Animais demarca várias diferenças entre animais, da mesma forma a Poética 1-3 demarca seu assunto mais amplo - área de imitações (mímeseis) - em tipos de meios de imitação (cores, formas, sons, movimentos, etc.), objetos imitados (coisas, ações, caracteres) e modos de imitação (narração, narração dramática e atuação). Tal como um tipo animal pode ser demarcado a partir de uma seleção dos traços de cada categoria de traços, da mesma forma as espécies poéticas também podem ser demarcadas por possuírem uma única distribuição de objetos, meios e modos de imitação. (DEPEW, 2007, p. 133). ${ }^{3}$

Com isso, Aristóteles define o objeto básico da Poética, qual seja, o estudo das produções miméticas (Poet. 1.1447a16). Antes de avançar para aquilo que mais interessa à presente investigação - isto é, a teoria aristotélica sobre as origens da poesia e do drama (ponto que será desenvolvido justamente como uma explicação das causas) -, convém tecer uma breve consideração sobre a mímēsis em Aristóteles.

É inegável que o autor herda a noção de mímēsis a partir do trabalho de Platão e, em linhas gerais, lida com ele de forma análoga à que fazia seu antigo mestre (VELOSO, 2000, p. 63). Há, contudo, uma diferença básica naquilo que ele empreende a partir desse ponto comum. A questão foi bem colocada por um estudioso da Poética nos seguintes termos:

A posição de Aristóteles tem uma afinidade com a de Platão, uma vez que ele aceita que toda arte ofereça imagens de realidade possível; mas ao

\footnotetext{
${ }^{3}$ No original: "Just as History of Animals marks off various differences among animals, so Poetics 1-3 marks off the large subject area of imitations (mimeseis) into kinds of objects imitated (things, actions, characters), media of imitation (colors, shapes, sounds, movements, etc.), and manner of imitation (narration, dramatic narration, and enactment). Just as an animal kind can be uniquely marked off by a selection of traits from each trait category, so, too, poetic species can be marked off by their possession of a unique distribution of objects, media, and manners of imitation."
} 
mesmo tempo é distante dela em espírito, já que a qualificação expressa por "possível" envolve um relaxamento crucial das demandas que Platão tinha feito pesar sobre a mimese, no que elas têm de mais preciso (ou desdenhoso). Embora compartilhe com ele o que pode ser chamado frouxamente de uma "teoria da correspondência" da mimese, Aristóteles contorna as implicações da visão de Platão sobre arte ao defender que o conteúdo e o sentido de trabalhos miméticos não podem justificadamente ser testados com qualquer critério fixo de verdade ou realidade. (HALLIWELL, 1989, p. 152-153). ${ }^{4}$

Em outras palavras, a diferença entre Platão e Aristóteles não reside tanto naquilo que compreendem sob o conceito de mimese, mas antes na atitude que demonstram com relação ao mundo sensível - sobre a possibilidade de conhecê-lo por meio dos sentidos -, ou seja, com relação ao objeto privilegiado da atividade mimética. Aristóteles reconhece nessa atividade uma possibilidade de lidar com algo que ultrapassa aquilo que Platão entendia como característico das aparências sensíveis - superficiais, externas, enganosas e corruptoras -, para enxergar nela uma oportunidade de exercício virtual, que, caso apresentasse uma estrutura unitária e lógica, poderia ser compreendida pelo pensamento, vindo inclusive a se tornar útil ao indivíduo que a ela se dedicasse. É interessante notar que essa revalorização da mimese como um meio de conhecimento prazeroso aberto a todas as pessoas (Poet. 4.1448b12-14) se revela um deslocamento radical com relação à República, embora não esteja tão afastada de certas proposições das Leis, no que tange à

\footnotetext{
${ }^{4}$ No original: “Aristotle's position has an affinity with Plato's, in that he accepts that all art offers images of possible reality; but at the same time it is remote from it in spirit, since the qualification expressed by 'possible' involves a crucial relaxation of the demands that Plato, at his most exacting (or dismissive), had brought to bear on mimesis. While sharing with him what might loosely be termed a 'correspondence theory' of mimesis, Aristotle circumvents the implications of Plato's view of art by holding that the content and meaning of mimetic works cannot justifiably be tested against any fixed criterion of truth or reality.
} 
tendência humana natural ao ritmo e à harmonia, bem como ao prazer que a humanidade tem em trabalhar a ordem por meio deles, desenvolvendo assim um determinado hábito em corpo e fala.

A partir dessa consideração básica sobre a mimese em Aristóteles - como meio de conhecimento prazeroso aberto a todas as pessoas -, é possível explicitar as razões por que o filósofo não concebe a poesia como mero reflexo de uma realidade qualquer (ligada aos diversos eventos da vida de um indivíduo, por exemplo), já que fatos assim seriam desprovidos de unidade (Poet. 8.1451a16-19). O importante para Aristóteles é sua disposição numa estrutura unitária que permita a inteligibilidade do mímèma. Em vista disso, a atividade do poeta não seria falar o que aconteceu, mas o que poderia acontecer, ou seja, "as coisas possíveis conforme a verossimilhança ou a necessidade (tà dynatà katà tò eikòs è tò anankaîon)" (Poet. 9.1451a36). Pela expressão katà tó eikós ("conforme a verossimilhança"), entende-se aqui a necessidade de que um enredo se desenvolva segundo a lógica, sem representar de modo irracional (álogon) suas ações dramáticas (Poet. 15.1454b6). Já a expressão katà tò anankaîon ("conforme a necessidade") remete ao fato de que um enredo deva apresentar coerência interna, só devendo se desenvolver - também de maneira lógica - a partir dos elementos já estipulados por ele próprio (Poet. 15.1454a33-36). Isso explica a aversão que Aristóteles apresenta pelo artifício do deus ex machina (apò mēkhanềs theós), uma vez que ele se revela um desenlace do enredo frequentemente inverossímil (porque contraria a lógica) ou incoerente, isto é, contrário à necessidade do enredo (porque não é um desdobramento de seus elementos internos).

Essa exigência lógica está fundamentalmente ligada à hierarquização dos elementos trágicos proposta por Aristóteles no cap. VI da Poética (1450a7-15). Embora seis sejam esses elementos básicos - enredo (mŷthos), caracteres (éthē), pensamento (diánoia), elocução (léxis), espetáculo (ópsis) e melopeia (melopoiía) -, o mais importante deles é a composição de ações (pragmátōn sýstasis), ou seja, o enredo. A escala de importância orientada segundo a eleição de um elemento do qual depende a inteligibilidade do todo trágico, além de ser um resultado da exigência lógica anteriormente mencionada, insere-se diretamente na 
filosofia ética aristotélica, segundo a qual o caráter só se expressa em termos de claras disposições para agir em determinados sentidos.

Feitos esses esclarecimentos básicos sobre o termo mímēsis na Poética - e seus desdobramentos teóricos -, convém retomar o modo de exposição analítico proposto a princípio. Após avançar uma definição da arte poética, o filósofo dedica um capítulo inteiro à explicação de suas causas. Como o objetivo da presente análise é compreender a teoria das origens da poesia e do drama em Aristóteles, sugerindo ainda as consequências e motivações da mesma, interessa citar este trecho integralmente:

Duas causas, ambas naturais, parecem ter originado a arte poética como um todo. Pois o mimetizar é natural às pessoas desde criança e nisso diferem dos outros animais, já que ele é o mais mimético e compõe seus aprendizados inicialmente por meio de mimese; e todos se comprazem com mímēmas.

Sinal disso é o que acontece com as obras: pois as coisas mesmas que observamos penosamente, comprazemo-nos ao contemplar suas imagens muitíssimo bem precisadas, tal como com formas de feras ignóbeis e cadáveres. A causa disso é que conhecer é agradável não apenas aos filósofos, mas também a todos os outros igualmente, ainda que participem menos disso. Pois assim se comprazem quando veem imagens, acontecendo de aprenderem ao vê-las e raciocinarem sobre o que é cada coisa (tal como "este é aquele"). E caso aconteça de não terem visto algo anteriormente, não há de ser o mímēma que fará o prazer, mas ele se dará pelo acabamento da obra ou pela cor ou por alguma outra causa.

Sendo-nos natural o mimetizar, a harmonia e o ritmo (pois é evidente que os metros são partes dos ritmos), desde o início aqueles nascidos para essas coisas, avançando aos poucos, originaram a poesia a partir de improvisações. A poesia dividiu-se conforme seus próprios caracteres: pois, de um lado, 
os mais veneráveis mimetizavam as belas ações e as de pessoas assim; por outro, os mais vulgares [mimetizavam] as ações dos infames, compondo primeiro invectivas, como aqueles compunham hinos e encômios. (ARISTÓTELES, Poet. 4.1448b41448b26).

Desenvolvendo um argumento análogo àquele proposto pelas Leis (2.653d), de Platão, para propor a tendência humana natural para a mimese e alguns de seus elementos - i.e., a harmonia e o ritmo -, bem como para o prazer que os mesmos provocam nos seres humanos, Aristóteles avança uma teoria sobre a origem natural da poesia. Aqui convém salientar a importância do papel gnosiológico e pedagógico que o filósofo atribui à mimese, sugerindo algo que subjaz também às palavras iniciais da Metafísica e, de forma ainda mais evidente, na Retórica (a partir de 1.1371b4). Esse mesmo ponto ainda será desenvolvido de forma complexa e consequente no interior da própria Poética, com sua teoria sobre o funcionamento da tragédia. Como se trata de um princípio basilar do pensamento aristotélico, essa intuição sobre a tendência humana natural à mimese e ao conhecimento constitui uma das chaves de compreensão da perspectiva positiva que Aristóteles tem acerca das performances poéticas e, mais especificamente, dramáticas.

Seguindo essa propensão inata, os seres humanos desenvolveram, a partir de improvisações inicialmente simples, diferentes formas de poesia - de acordo com uma dicotomia em que se dividiam seus próprios caracteres: uns elaboraram formas de poesia mais afins à dignidade e à seriedade, como o hino e o encômio; outros, formas poéticas mais relacionadas à baixeza e à comicidade, como a invectiva (psógos) e o ridículo (geloîon). Convém notar que, assim como os princípios da poesia são naturais, sua divisão segundo os caracteres humanos também é de ordem natural: poetas de determinada propensão ética farão determinados tipos de poesia, enquanto os demais se dedicarão aos outros tipos.

Em todo caso, o mais importante para uma análise da teoria aristotélica sobre as origens do drama apenas se revela na continuação daquela passagem e convém retomá-la aqui também na íntegra a fim de se desenvolver o que está sugerido por Aristóteles a esse respeito: 
Dentre os poetas de invectivas, não temos como apontar um tal poema antes de Homero, mas devem ter existido muitos; isso tem início a partir de Homero, como com o Margites dele e outros assim. Nesses, segundo a harmonia, foi introduzido o metro iâmbico - e, por causa disso, é agora chamado iambo, pois nesse metro eles iambizam [injuriam] os outros. Entre os antigos, uns se tornaram poetas de versos heroicos; outros, de versos iâmbicos. Assim como Homero foi o maior poeta quanto a poemas sérios - pois ele é o único que não apenas compôs bem, mas também [compôs] mimeses dramáticas -, assim também ele primeiro delineou o arranjo da comédia - dramatizando não a invectiva, mas o cômico. Pois o Margites é algo análogo: assim como a Ilíada e a Odisseia estão para as tragédias, assim também aquele está para as comédias. Surgindo a tragédia e a comédia, cada poeta se lançou, conforme a natureza que lhe era própria, a cada forma de poesia: uns se tornaram compositores de comédias, em vez de iambos; outros, mestres de tragédia, em vez de epopeias. Isso porque essas formas são mais complexas e mais estimadas do que aquelas. [...] Tendo surgido então a partir de um início improvisado tanto a tragédia quanto a comédia: a primeira provém daqueles que conduzem o ditirambo; a outra, dos que conduzem os cantos fálicos, que são ainda hoje muito estimados em nossas póleis. A tragédia ampliou-se avançando aos poucos, os poetas desenvolvendo o que nela se manifestava. E, tendo passado por muitas transformações, a tragédia se fixou, depois de alcançar a própria natureza. Ésquilo foi quem primeiro levou o número de atores de um para dois, diminuiu as partes do coro e preparou o diálogo [lógos] para desempenhar o papel de protagonista. Sófocles elevou o número para três e introduziu a cenografia. Além disso, com relação à extensão, a partir de histórias breves e de uma elocução ridícula, por ter se transformado a partir do elemento satírico, alcançou tardiamente a gravidade, 
enquanto o metro passou do tetrâmetro ao iâmbico. Pois primeiro faziam uso do tetrâmetro, porque a forma da poesia era satírica e associada à dança, mas, quando o diálogo foi introduzido, a própria natureza da tragédia descobriu qual era o metro apropriado; pois, de todos os metros, o mais apropriado à fala é o iâmbico. Sinal disso é que dizemos muitíssimos trímetros iâmbicos quando falamos em linguagem de conversa com os outros, mas hexâmetros poucas vezes, apenas afastando-nos da harmonia da linguagem de conversa. (ARISTÓTELES, Poet. 4.1448b261449a9-31).

Muitos intérpretes apontaram as contradições e problemas dessa passagem, evocando, por exemplo, as variantes de alguns termos nas diferentes tradições manuscritas - como a palavra phaulliká ao invés de phalliká (em Poet. 4.1449a12), não apenas aludindo ao caráter trivial e simples dessas representações originais (conforme o significado da palavra phaûlos), mas colocando em dúvida essa pretensa origem fálica da poesia cômica (seja porque sequer estivesse presente na formulação original de Aristóteles, seja porque algum copista dessa tradição manuscrita não via sentido no emprego de tal palavra). Apesar do aspecto problemático do trecho, acreditamos ser possível propor uma interpretação coesa de seu sintético e complicado texto. Tentando concentrar suas informações da forma mais coerente possível (suplementando-as ainda, quando necessário, com outras passagens da Poética), é possível sugerir os seguintes pontos:

* Homero foi o primeiro responsável por desenvolver uma certa noção de "drama", qual seja, o emprego da mimese para se falar numa primeira pessoa que não coincida com a pessoa do próprio poeta, ${ }^{5}$ contudo, não desenvolveu o drama propriamente dito, uma vez que continuou

\footnotetext{
${ }^{5}$ Tal definição de "drama" é tornada possível quando se combinam as seguintes passagens da Poética: 4.1448 b37 e 24.1460a7.
} 
a realizar a mimese com uma métrica uniforme e, em grande parte, "por meio da narração [di' apangelías]" (Poet. 5.1449b10);

* os cantos fálicos - liderados por um exarconte (líder de uma performance poética de coral) e ainda estimados nas póleis do tempo de Aristóteles - estão na base daquilo que veio a se tornar a comédia;

* um ditirambo arcaico - liderado por um exarconte; dotado de caráter satírico e associado à dança; com histórias breves, elocução ridícula e tendo por metro o tetrâmetro trocaico - foi o gênero a partir do qual se desenvolveu pouco a pouco a tragédia - encenada por atores; dotada de caráter sério e associada ao diálogo; com histórias de certo tamanho, linguagem ornamentada e tendo por metro o iambo para as partes dialogadas;

* o aumento do número de atores e a diminuição do papel do coro - ambos os movimentos inaugurados por Ésquilo - conduziram a tragédia até o que era próprio de sua natureza: nesse sentido, a preponderância do enredo (mŷthos) em detrimento do espetáculo (ópsis) é mais uma vez reforçada;

* a adoção gradual do metro iâmbico pela tragédia não apenas ilustra o desenvolvimento natural do ritmo no interior da história do gênero, mas indica a crença aristotélica de que a linguagem da tragédia deveria se aproximar do discurso cotidiano.

Cumpre observar que as poucas informações oferecidas por Aristóteles acerca das origens da comédia são justificadas no capítulo seguinte com base na falta de interesse que os antigos tiveram pelo início das performances cômicas, não se preocupando em registrar seu desenvolvimento gradual (Poet. 5.1449a38). Esse ponto é tradicionalmente mencionado para se defender - acertadamente - que, 
se Aristóteles admite não possuir informações históricas precisas sobre os primórdios da comédia, por outro lado, acredita ter acesso a detalhes históricos seguros o bastante no que concerne à origem da tragédia. Isso, obviamente, não diminui o fato de que o filósofo esteja propondo um esquema teórico fortemente analítico, no qual tenta encaixar o desenvolvimento histórico dos gêneros poéticos helênicos (conforme alertam certos comentadores da Poética).

Um ponto normalmente encarado como problemático nessa passagem - embora a interpretação acima sugerida o evite - tem relação com a ordem da argumentação avançada por Aristóteles para abordar a evolução dos gêneros dramáticos: dando a entender que a tragédia e a comédia surgiriam na sequência de sua distinção entre poesias que se dedicavam à mimese de diferentes objetos -i.e., o hino e o encômio tendo por objeto as belas ações, enquanto a invectiva se voltaria para as ações de homens infames (Poet. 4.1448b4) -, o texto da Poética não afirma que a tragédia venha do hino ou do encômio, nem que a comédia venha da invectiva. Ao invés de continuar um relato sobre a evolução dos gêneros poéticos, Aristóteles afirma que, depois de terem surgido os gêneros dramáticos, eles substituíram os gêneros então existentes no gosto dos poetas, porque eram formas mais complexas (tò meízō) ${ }^{6}$ e mais estimadas (entimótera): dentre os gêneros elevados, as tragédias substituíram as epopeias; dentre os gêneros baixos, as comédias substituíram os iambos (Poet. 4.1449a2-7). Na sequência da argumentação, abandonando a distinção entre poesias com base em seus objetos (hino/encômio/ epopeia; invectiva/cômico/iambo), Aristóteles traz gêneros poéticos cuja origem não especifica claramente: ditirambos e cantos fálicos. Trata-se, portanto, de um desenvolvimento teórico paralelo àquele que delineara

\footnotetext{
${ }^{6}$ A tradução de meízō aqui por "mais complexas" e não por "maiores" justifica-se na medida em que o próprio Aristóteles diferencia os gêneros dramáticos dos épicos não porque aqueles sejam "maiores" do que estes (antes o contrário seria verdade, Poet. 5.1449 b12), mas porque há um aumento na complexidade dos gêneros dramáticos responsável por torná-los mais aptos a atingir o fim da arte poética (Poet. 26.1462b1215). Essas informações dizem respeito explicitamente à tragédia (em sua relação com a epopeia), mas, mutatis mutandis, são aplicáveis também à comédia (em sua relação com o iambo).
} 
anteriormente. Nesse sentido, o fato de que o ditirambo seja descrito como possuidor de caráter satírico não contradiz o que ele afirmara há pouco sobre a seriedade do hino, do encômio ou da epopeia, pois não afirma que o ditirambo constitua a seus olhos uma modalidade desenvolvida a partir de um desses gêneros. Da mesma forma, não parece que os cantos fálicos constituam para Aristóteles um desdobramento da invectiva ou do cômico. Embora esses pontos se deem a ver claramente a partir do texto da Poética, essas observações não foram feitas por nenhum dos estudos aqui consultados e parecem constituir uma interpretação original dessa passagem. Os intérpretes tendem a assumir que Aristóteles subentenderia o ditirambo como mera modalidade do hino, mas a única forma de respeitar o texto dessa passagem - propondo uma interpretação coerente da mesma - é sugerindo a existência de um redirecionamento da discussão a partir da metade do capítulo IV da Poética, em 1449a2.

Outro ponto importante a ser observado por quem queira delinear a teoria aristotélica da origem dos gêneros dramáticos é que - assim como os cantos fálicos continuaram a ser executados depois de terem dado origem à comédia, que passou a se desenvolver independentemente deles - o ditirambo continuou a ser executado depois de ter dado origem à tragédia. Inclusive, a julgar pelo elemento satírico de que é dotado o ditirambo arcaico mencionado por Aristóteles, é de se supor que em seu esquema diacrônico de evolução dos gêneros dramáticos, tanto a tragédia quanto o drama satírico tenham se desenvolvido a partir do ditirambo. Nesse sentido, esse esquema poderia ser assim delineado:

FIGURA 1 - Esquema diacrônico de evolução dos gêneros dramáticos

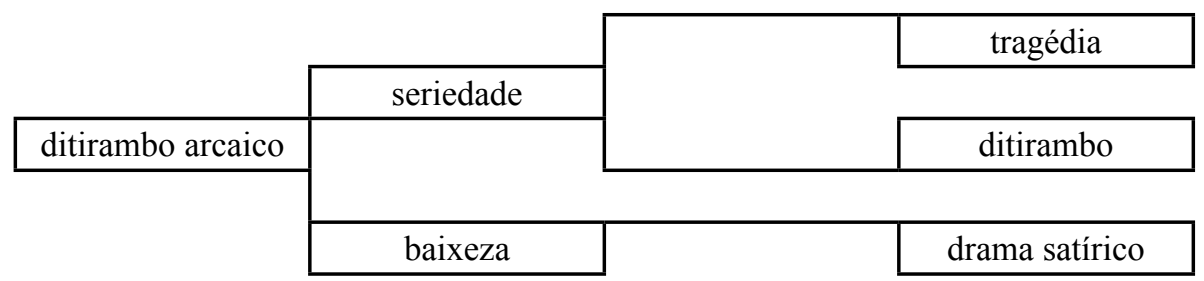


Ainda que o esquema seja menos simétrico do que aquele proposto por outros estudiosos - e tenha que preencher certos silêncios do texto aristotélico, na medida em que postula uma diferenciação com base nos objetos da mimese entre tragédia e ditirambo, por um lado, e drama satírico, por outro (algo que não é explicitamente proposto por Aristóteles) -, essa conformação dá conta dos gêneros poéticos historicamente executados durante as Grandes Dionísias, por exemplo, e não contradiz em nenhum ponto o texto da Poética.

Um aspecto interessante desse arranjo teórico é que ele coincide, em linhas gerais, com uma ideia básica subjacente aos esquemas propostos por Platão na República e nas Leis. Nesses diálogos, a sugestão comum é a de que os gêneros mais simples - como os hinos e os encômios - teriam sido os primeiros a ser compostos pelos seres humanos e que apenas com o desenvolvimento de sociedades mais luxuosas e desregradas - i.e., menos dispostas a se restringir às coisas simples e necessárias - é que os gêneros dramáticos teriam vindo a se desenvolver. Nesse sentido, a ideia é de que esses gêneros mais complexos teriam se desenvolvido a partir de um rompimento com os limites dos gêneros antigos mais simples. Essa compreensão básica é a mesma que subjaz ao arranjo teórico proposto na Poética. A diferença, contudo, é que, enquanto Platão censura as formas mais complexas e desenvolvidas de poesia, propondo um retorno aos modelos poéticos mais simples e severos, Aristóteles mostra-se contente com a evolução da poesia e considera positivo que as formas mais arcaicas deem lugar paulatinamente a formas mais desenvolvidas de composição poética. Não se trata, portanto, de uma revisão (ou correção) das premissas teóricas propostas pelos arranjos de Platão, mas de uma discordância com relação à visão de mundo a partir da qual tais arranjos deveriam ser avaliados. Os motivos para essa discordância - e para outras discordâncias (já vistas ou ainda por analisar) - se tornarão explícitos quando se compreender em que consiste a demonstração conclusiva da essência da poesia - e, mais especificamente, da tragédia.

Depois de oferecer uma definição básica do campo da arte poética (nos caps. I-III), uma explicação de suas causas (nos caps. IV-V), Aristóteles dedica grande parte dos capítulos seguintes a demonstrar a 
essência do fenômeno poético, principalmente em sua modalidade mais bem-acabada e complexa, que é a tragédia. A fim de que se compreenda o que está em jogo nesse novo desdobramento da obra, valerá a pena retomar sua célebre "definição da essência [hóron tềs ousías]" da tragédia. Antes, contudo, cabe destacar que o papel primário de uma "definição da essência" nas obras de Aristóteles é,

por um lado, servir como princípio a partir do qual um determinado tipo se configura como unidade genuína, por outro, mostrar dedutivamente por que suas propriedades subordinadas estão organizadas de modo tal que a substância, a prática ou o tipo de poíesis em questão podem efetivar seu érgon [efeito] ou sua função distintiva. Uma unidade genuína é necessária se as partes e outros traços de um determinado tipo formarem uma hierarquia objetiva num todo funcional. (DEPEW, 2007, p. 139). ${ }^{7}$

Isso se aplica a muitas das obras de Aristóteles, principalmente àquelas que dedica aos animais, ${ }^{8}$ e deve ser levado em conta na interpretação que se dê à Poética quando se considera a seguinte passagem:

Falaremos depois, então, sobre a arte mimética em hexâmetros e sobre a comédia. Falemos agora sobre a tragédia, retomando dela, a partir do que foi dito, a definição de sua essência. É pois a tragédia a mimese de uma ação séria, completa e de certa extensão, em linguagem ornamentada, com cada espécie de ornamento distribuída em suas partes,

\footnotetext{
${ }^{7}$ No original: "[...] the primary role of a 'formula of the essence' is to serve as a principle from which it can be seen that the kind in question is a genuine unity and to show deductively why its subordinate properties are organized in such a way that the substance, practice, or kind of poiesis in question can realize its ergon or distinctive function. Genuine unity is needed if the parts and other traits are to form an objective hierarchy in a functional whole."

${ }^{8}$ Exemplos mencionados por Depew (2007, p. 139) são: Part. an. 1.1.640a33-7; Ph. 2.6.197b2-37.
} 
sendo executada por meio de agentes que dramatizam e não de uma narração, capaz de levar - por meio de compaixão e temor - à catarse de tais emoções. (ARISTÓTELES, Poet. 6.1449b20-27).

Muito poderia ser afirmado sobre cada um dos termos dessa "definição da essência [hóron tềs ousías]", mas aqui convém destacar aquilo que serve como princípio a partir do qual se organizam as diferentes propriedades da tragédia a fim de que seu érgon ("efeito") possa ser bem efetivado. Que esse érgon seja justamente a catarse das emoções suscitadas durante uma tragédia, a definição acima não permite ignorar. O princípio organizador das diferentes partes da tragédia, contudo, não está explícito aí, uma vez que só vem a ser formulado na sequência do argumento. Depois de definir as seis partes da tragédia - enredo (mŷthos), caracteres (éthē), pensamento (diánoia), elocução (léxis), espetáculo (ópsis) e melopeia (melopoiía) (Poet. 6.1450a9) -, Aristóteles sugere o seguinte:

O enredo é então o princípio [arkhè], e como que a alma, da tragédia; em segundo lugar, estão os caracteres [...]. A tragédia é a mimese de uma ação e, por causa desta, sobretudo [a mimese] dos que agem. Em terceiro lugar, o pensamento: isso é ser capaz de dizer o que é pertinente e adequado [...]. A quarta [parte], †com relação à linguagem $\uparrow$, é a elocução. Entendo por "elocução", como primeiro disse, a manifestação de sentido por meio do emprego da palavra, e que possui a mesma capacidade em versos ou em prosa. Com relação às partes restantes, a melopeia é o maior dos ornamentos, enquanto o efeito visual do espetáculo cênico, embora o mais capaz de conduzir os ânimos, é o menos afim à arte poética e o que lhe é menos próprio. Pois a força da tragédia existe sem a competição e os atores; além disso, para a execução dos efeitos visuais, mais vale a arte do cenógrafo do que a dos poetas. (ARISTÓTELES, Poet. 6.1450a37-1450b20). 
Tal como anteriormente proposto, essa hierarquização das partes da tragédia atende a um dos pressupostos básicos da teoria de Aristóteles, qual seja, o de que o mímēma deva ser inteligível a fim de que o mais próprio de sua essência - i.e., a catarse da compaixão e do temor despertados ao longo da peça - possa ser efetivado. Ainda assim, outros pontos são igualmente importantes na determinação dessa hierarquia, afinal, de que modo o enredo (mŷthos) pode assegurar o efeito (érgon) da tragédia? Isto é, de que modo o enredo orientará os elementos da tragédia a fim de que ela seja capaz de suscitar compaixão e temor, levando à catarse dessas afecções? Isso se deve justamente ao fato de que o enredo constitui o elemento responsável por assegurar a melhor maneira para que tais afecções sejam suscitadas junto ao público. Com relação a isso, um primeiro ponto que foi salientado pela maioria dos comentadores diz respeito à necessidade de se criarem as condições de empatia entre público e personagens. Para haver essa empatia, é preciso que os caracteres das personagens não sejam totalmente estranhos àqueles que fazem parte da experiência do público. Por isso, Aristóteles recomenda que a personagem se mostre

sem se diferenciar muito pela virtude ou pela justiça [ho méte aretềi diaphérōn kai dikaiosýnēi] e sem mudar para o infortúnio por causa da maldade ou da vileza, mas por alguma falibilidade [méte dià kakian kaì mokhthērian metabállōn eis tèn dystykhian allà di'hamartian tiná [...]. (ARISTÓTELES, Poet. 13.1453a7-12).

Tal recomendação busca, sobretudo, criar entre o público e as personagens uma empatia que ultrapasse a mera apreensão intelectual. Se, por um lado, a inteligibilidade de que todo enredo baseado numa ação unitária é dotado coloca-se como condição necessária para a existência de qualquer tragédia, ela não é condição suficiente para suscitar a identificação entre o público e a ação encenada. Nesse sentido, alguma proximidade entre as personagens e o público, do ponto de vista dos caracteres (⿳亠丷厂犬th $\bar{e})$, é outra condição fundamental para que determinadas afecções possam ser suscitadas convenientemente em quem presencia a tragédia. 
Para Aristóteles, é preciso que seja possível haver certa identificação entre o público e as personagens, fato que se daria justamente por seu caráter intermediário (que não se destacaria, desse modo, nem positivamente nem negativamente). Ainda que essas personagens medianas devam apresentar uma dignidade ligeiramente acima do comum (tal como especificado em Poet. 5.1449b9-10), é necessário que elas tenham certa falibilidade (hamartía). O detalhe é que isso deve se manifestar de um modo que não abale profundamente sua relativa excelência moral, ou seja, elas devem falhar não por causa de uma falta de caráter, mas devido a certa ignorância (ágnoia).

$\mathrm{O}$ desastre trágico deve revelar-se imerecido, porque suas razões devem estar relacionadas à falha de alguém. Isso leva o público à compaixão (uma vez que a consequência da falha não parece ser um castigo merecido) e ao temor (já que qualquer um poderia ser levado a cometer o mesmo tipo de falha). De toda forma, segundo a concepção aristotélica, para que essas emoções possam ser sentidas pelo público, é preciso que se compreenda um envolvimento causal entre os agentes e os eventos que trazem a mudança de destino. Ainda assim, para evitar que isso implique numa pesada carga de culpabilidade - capaz de levar a um questionamento inclusive do êthos da personagem -, é preciso que esses agentes tenham originalmente agido sob os impulsos da ágnoia ("ignorância"), fato responsável por levá-los a cometer o que viria a se revelar sua hamartía ("falibilidade").

Nesse sentido, a noção de hamartía tem mais relação com a ação condenável praticada por uma personagem que agia sem pleno conhecimento das circunstâncias envolvidas nela - e, assim, por uma personagem não condenável da perspectiva de suas motivações -, do que com um defeito moral da personagem, como defendem Dupont-Roc e Lallot (1980b, p. 243-6). Nesse sentido, as seguintes palavras refletem melhor o arranjo sugerido pela Poética:

[Os insights tornados possíveis a partir de uma perspectiva ética] podem ser usados para aumentar a compreensão da hamartía trágica (ou erro [missingthe-mark]). Pois, apesar das milhares de páginas escritas sobre essa noção, ainda se faz necessária uma 
explicação que dê conta inteiramente das maneiras pelas quais, para Aristóteles, o erro prático pode acontecer devido a certas causas diversas do vício de caráter e, ainda assim, ter importância para a vida. A tragédia ocupa-se de boas pessoas que vêm a sofrer "não por causa de um defeito de caráter ou vileza, mas por causa de alguma hamartía" (Poet. 13.1453a9-10). Hamartía e hamartēma são claramente distinguidos de uma falha ou um defeito de caráter, tanto aqui quanto em outros lugares (EN 5.8.1137b11, cf. Rhet. 1374b6). (NUSSBAUM, 2001 [1986], p. 382). ${ }^{9}$

De tudo quanto ficou dito, está claro que o conceito de hamartía constitui uma espécie de saída para um conflito criado pela própria teoria trágica de Aristóteles. Por um lado, um princípio quer que o enredo seja lógico, a fim de que possa ser compreendido pelo público. Por outro, é necessário que os agentes - apesar de terem cometido uma falha que vai levá-los à mudança de fortuna e pela qual são responsáveis em última instância - não se revelem voluntariamente culpados (a fim de que o público ainda seja capaz de se identificar com eles). Ora, a única maneira de se garantir que alguma inocência coexista com a quebra dos mais hediondos tabus da sociedade helênica é sugerir que tais ações tenham sido perpetradas sem que seus agentes soubessem o que faziam: assim está garantido o papel da ágnoia nos principais enredos trágicos, que, tal como ficará claro em breve, são justamente os que Aristóteles recomenda como os melhores (Poet. 13.1452b30-35), chamando-os "enredos complexos".

\footnotetext{
${ }^{9}$ No original: "There are many areas in which we could use these insights to press Poetics interpretation further. [...] They can also be used to increase our understanding of tragic hamartia, or missing-the-mark. For despite the thousands of pages that have been written on this notion, we still need an account that is fully responsive to the ways in which, for Aristotle, practical error can come about through some causes other than viciousness of character and still matter to the value of a life. Tragedy concerns good people who come to grief 'not through defect of character and wickedness, but through hamartia' (1453a9-10). Hamartia and hamartēma* are sharply distinguished from flaw or defect of character, both here and elsewhere (ENV.8, 1147b11ff., cf. Rhet. 1374b6ff)."
} 
Antes de passar a essas considerações, contudo, convém explicitar lateralmente as razões para que a definição aristotélica de tragédia se encontre tão fundamentalmente ligada à ideia de se suscitar a compaixão e o temor. Para isso, é necessário remeter à noção de kátharsis, uma vez que o primordial no caso da tragédia não é apenas suscitar tais afecções, mas por meio disso ser capaz de despertar o prazer trágico e a kátharsis das mesmas. Já foi notado inúmeras vezes que a motivação de Aristóteles para desenvolver essa teoria parece se compreender como resposta à crítica platônica segundo a qual as emoções fortes da tragédia seriam perniciosas para a alma do público (Rep. 10.603b-606d). A Poética não nega que a tragédia seja efetivamente capaz de suscitar as emoções fortes censuradas pelo Sócrates da República, mas tenta compreendê-las sob uma perspectiva diferente da que é aí defendida. Contudo, em que pese a importância desse conceito na Poética, revela-se difícil propor uma definição precisa de kátharsis, já que o próprio Aristóteles se furta a fazê10. ${ }^{10}$ Já houve quem tenha desejado relacioná-lo a pretensas considerações fisiológicas pretensamente outrora em voga, mas o ponto mais próximo de algum consenso atualmente é a ideia de que a kátharsis tenha aspectos propriamente intelectuais de um aprendizado clarificador.

Seja como for, é possível sugerir que na Poética esse mecanismo seja definidor da tragédia e constitua o grande trunfo da teoria de Aristóteles para responder a um questionamento radical sobre a utilidade que a tragédia poderia ter. Além disso, considerando o emprego da palavra kátharsis por Platão, é lícito supor que a teoria aristotélica constitua um questionamento ainda mais radical da prática pedagógica defendida por seu mestre. No Sofista (230c-d) - conversando com Teeteto, Sócrates e Teodoro -, "o estrangeiro de Eleia [ho xénos ex Eléas]" propõe as seguintes considerações sobre os que praticam o método dialético pautado pelo élenkhos ("refutação"):

${ }^{10} \mathrm{O}$ termo só aparece duas vezes na Poética (6.1449b28 e 17.1455b15), ambas de forma igualmente não especificada, como bem destacado por Veloso (2004, p. 15). O estudioso alude ainda ao fato de que na Política (8.6-7), tratando de uma modalidade de kátharsis levada a cabo pela música, Aristóteles "esclarece" esse conceito remetendo o leitor ao que é dito na Poética. Ou seja, "a coisa ganha feições labirínticas" (VELOSO, 2004, p. 17). 
Eles questionam alguém que julga dizer algo de valor acerca de alguma coisa, embora nada diga; em seguida, verificam facilmente que tais opiniões estão erradas e, aproximando-as por meio do diálogo de um mesmo ponto, confrontam umas com as outras e demonstram, através desse confronto, que umas são contrárias às outras com relação aos mesmos objetos, sob os mesmos pontos de vista. Percebendo-o, os interlocutores indispõem-se consigo mesmos e mostram-se mais abertos aos outros - desse modo, com efeito, livram-se de todas as suas opiniões orgulhosas e frágeis, sendo agradável para quem escuta essa liberação, além de um benefício seguro para quem a ela se submete. Ó meu caro jovem, pois aqueles que se purificam [hoi kathaírontes autoús] pensam como os médicos responsáveis pelos corpos, os quais concordam que o corpo não é capaz de gozar da nutrição que se lhe oferece antes que se remova qualquer obstáculo existente em seu interior. $\mathrm{O}$ mesmo também pensam aqueles sobre a alma: pois não terá benefício algum dos conhecimentos que lhe forem aportados sem antes ter sido refutado e colocado em seu devido lugar - pela vergonha de ser refutado -, desfazendo-se das opiniões que impedem as vias para os conhecimentos até que se mostre purificado [katharòn] e convencido de saber apenas as coisas que de fato sabe, nada além disso. (Pl. Sph. 230b-d).

Outros trechos do corpus platonicum poderiam ser aduzidos para dar a ver algo análogo, ${ }^{11}$ mas nessa passagem específica, a sugestão é

${ }^{11}$ Depois de uma breve incursão pela história do conceito de kátharsis (e seus derivados) em autores antigos, sugerindo que seu sentido teria relação com a ação mais concreta de "remoção" e "limpeza", Nussbaum (2001 [1986], p. 389) avança as seguintes reflexões sobre seu emprego por Platão: "If we now return to Plato's usage, we find that he preserves this general picture. The central sense is that of freedom from admixture, clarity, absence of impediment. In the case of the soul and its cognition, the application of the word-group is mediated by the dominant metaphors of mud and 
a de que um tipo de kátharsis intelectual seria suscitado pelo élenkhos ("refutação") elaborado no interior de uma discussão guiada pelo método dialético e que apenas por meio desse expediente haveria a possibilidade do desenvolvimento de alguma forma de conhecimento seguro. O que está em questão nesse trecho é o método dialético tal como delineado em inúmeros diálogos socráticos escritos por Platão (mencionados por Aristóteles com o nome de Sōkratikoì lógoi, em Poet. 1.1447b11). Se estiver correta a hipótese de que esse tipo de escrito era empregado na Academia como meio de treinar o método dialético - tal como sugerido por Kahn (1996, p. 56) e Depew (2007, p. 144) -, é possível afirmar que, para Platão, a kátharsis seria um dos efeitos propiciados pela leitura de seus diálogos socráticos, principalmente dos aporéticos. Tragédias e outras formas de arte mimética, por outro lado, seriam meros estímulos responsáveis por afetar o caráter através de um mecanismo pouco racional de imitação, tendendo a exercer uma influência antes negativa do que positiva e não sendo, por isso, capazes de suscitar algum tipo de kátharsis. Tal parece ser o posicionamento de Platão.

No entanto,

clean light: the eye of the soul can be sunk in the mud (Rep. 533d1,Phd. 69c), or it can be seeing cleanly and clearly. Katharos cognition is what we have when the soul is not impeded by bodily obstacles (esp. Rep. 508c, Phd. 69c). Katharsis is the clearing up of the vision of the soul by the removal of these obstacles; thus the katharon becomes associated with the true or truly knowable, the being who has achieved katharsis with the truly or correctly knowing (esp. Phd. 65ff., 110ff..). Thus we even find expressions such as katharōs apodeixai, meaning 'demonstrate clearly' (Crat. 426b)" "'Se agora nos voltarmos para o uso de Platão, descobrimos que ele preserva essa figura geral. $\mathrm{O}$ sentido central é o de ausência de mistura, clareza, ausência de impedimento. No caso da alma e sua cognição, a aplicação de palavras desse étimo é mediada por metáforas predominantemente de lama e luz clara: o olho da alma pode ser afundado na lama (Rep. 533d1, Phd. 69c) ou pode estar vendo limpa e claramente. Uma cognição em modo kátharos é o que temos quando a alma não está impedida por obstáculos corporais (especialmente Rep. 508c, Phd. 69c). Kátharsis é a limpeza da visão da alma por meio da remoção desses obstáculos; então o kátharon torna-se associado com o verdadeiro ou verdadeiramente conhecível, o ser que atingiu kátharsis com saber verdadeiro ou correto (esp. Phd. 65ff., 110ff.). Então até encontramos expressões como katharôs apodeîxai significando 'demonstrar claramente' (Crat. 426b)"). 
Aristóteles discorda. Por um lado, ele afirma na Política que hinos entusiásticos e iambos ritualizados servem um propósito catártico e não apenas estimulante, ainda que seja um processo em que as pessoas evanescentemente "extraem algo de seus sistemas" (Pol. 8.5.1340a8-14; 8.6.1341a14-24; 8.7.1342a16-28; 7.17.1336b20). Na Poética, ele afirma algo diferente: que trabalhar com enredos trágicos -e não apenas diálogos platônicos e outros materiais textualizados de mesmo tipo - é catártico também, ou seja, purificador porque oferece clareza intelectual no sentido que Platão privilegia na passagem citada [do Sofista]. (DEPEW, 2007, p. 145). ${ }^{12}$

Nesse sentido, fica cada vez mais claro o intuito de Aristóteles ao desenvolver sua teoria da kátharsis das emoções suscitadas pela tragédia: seja por meio de uma resposta às críticas que Platão elaborara na República contra as pretensões educadoras da tragédia (a partir dos argumentos psicológicos ali avançados), seja por meio de uma resposta de viés cognitivo à proposta pedagógica explícita num trecho como o do Sofista (segundo a qual apenas o método dialético refutativo suscitaria a kátharsis intelectual necessária ao verdadeiro conhecimento), Aristóteles promove - com argumentos filosóficos - uma reavaliação do papel que a tragédia ainda poderia vir a desempenhar na paideía humana. Com a Poética, o filósofo sugere não apenas que uma tragédia - quando bem executada - tem uma função pedagógica importante, mas, igualmente, que não é papel da filosofia propor meios de substituir a função catártica já realizada por uma tragédia bem executada. Tomando como paradigma da relação entre filosofia e poesia a própria Poética, seria possível sugerir

\footnotetext{
${ }^{12}$ No original: "Aristotle disagrees. For one thing, he claims in Politics that enthusiastic hymns and ritualized iambics do serve a purifying and not just a stimulating purpose, albeit one in which people evanescently 'get something out ot their systems' (Pol. 8.5, 1340a8-14; 8.6, 1341a14-24; 8.7, 1342a16-28; 7.17, 1336b20). In Poetics, he claims something else: that working through tragic plots, and not just Platonic dialogues and other such textualized materials, is cathartic as well, purifying because it gives intellectual clarity in the sense Plato privileges in the passage just quoted."
} 
que, para Aristóteles, o papel da filosofia seria justamente oferecer certos direcionamentos para que o tragediógrafo - valendo-se de seus meios (muito mais aptos do que aqueles disponíveis ao filósofo) - efetue uma verdadeira kátharsis.

Nesse sentido, é preciso observar que, embora parta de uma série de definições descritivas da arte poética, essa obra se destaca muito mais pelas prescrições oferecidas aos poetas com o intuito de que componham de modo a efetivar aquilo que constitui para Aristóteles a essência da poesia. É possível compreender tanto a hierarquização das partes da tragédia quanto a prescrição de determinados enredos trágicos - em detrimento de outros - como meros desdobramentos do que Aristóteles define como a "essência" (ousía) da tragédia. Ou seja, o caráter positivo imputado a conceitos como reviravolta (peripéteia) e reconhecimento (anagnốrisis) explica-se por sua relação fundamental com o mecanismo reconhecido na Poética como essencialmente trágico, qual seja, a kátharsis. Consequência disso é que Aristóteles considere a presença de ambos os expedientes como ingrediente imprescindível dos melhores enredos trágicos (Poet. 11.1452a37).

Para o filósofo, as tragédias são produtos de arte racional, cujo sucesso depende da coerência de sua estrutura, devendo ser capazes de suscitar a compaixão e o temor naqueles que os presenciam. Levando isso em conta, nada poderia ser mais lógico do que a constatação de que agentes do enredo trágico, motivados por um equívoco fundamental e, apesar de não serem moralmente condenáveis, agindo para a própria desgraça, despertem no público os mais extremos sentimentos de compaixão e temor precisamente no instante em que, dando-se conta de sua falha, se encontram a ponto de sofrer uma mudança conforme a verossimilhança ou a necessidade do enredo, mas de forma inesperada e brusca, com relação àquilo em que acreditavam.

Com isso, a abordagem aristotélica revela-se - muito mais do que a platônica - aberta à compreensão do papel que determinada poesia poderia ter, inclusive como objeto legítimo de ocupação filosófica. Onde Platão demonstrara certa intolerância com a maior parte da produção poética de sua época - ainda que, mesmo nos momentos mais 
acerbos de sua crítica, algumas modalidades de poesia sempre tenham sido poupadas -, Aristóteles promoveu um modo de leitura diferente. $\mathrm{O}$ caráter prescritivo de determinadas passagens de sua análise não permite propor que esse "modo diferente" tenha rompido de todo com a imposição arbitrária de certos valores pelo filósofo - como é típico da preceptística clássica -, mas é certo que a poesia recebe o reconhecimento de seu estatuto como campo discursivo com um potencial distintivo, a ser avaliado a partir da apreensão de axiomas críticos próprios dela enquanto arte (tékhnē).

Antes de encerrar essas considerações, contudo, cabe sugerir de que modo a teoria sobre as origens da poesia e do drama desempenha um papel fundamental no arranjo proposto na Poética. É certo que, ao contrário do que já pôde ser sugerido sobre a falta de interesse de Aristóteles pela origem dos fenômenos poéticos, o filósofo conciliou de forma brilhante a necessidade de propor um modelo poético capaz de responder aos questionamentos radicais colocados em várias das obras de Platão e, ao mesmo tempo, interpretar os dados históricos e teóricos básicos com que tinha inevitavelmente que lidar.

As motivações para que Aristóteles propusesse seu modelo poético podem ser compreendidas a partir de seu interesse em garantir o emprego de um novo gênero de discurso pela filosofia, qual seja, o tratado filosófico, em detrimento do gênero mimético que vinha sendo praticado por Platão e pelos membros da Academia, isto é, o diálogo socrático. Tratando em sua Poética daquilo que se pode esperar da arte dedicada à realização de obras miméticas - cujo ápice Aristóteles faz questão de afirmar que é a tragédia (em sua forma complexa) e não o diálogo socrático ou qualquer outro tipo de composição mimética -, o filósofo defende que os maiores benefícios intelectuais propiciados por uma obra mimética desse tipo estariam ligados à kátharsis da compaixão e do temor suscitados por ela. Isso está longe de ser uma defesa do uso filosófico das composições miméticas, mas certamente representa um avanço com relação ao tratamento anteriormente proposto por Platão, na medida em que não lhe impõe critérios de verdade e moralidade externos ao campo da atividade poética (ainda que também lhe faça 
certas exigências, como a de unidade e a de inteligibilidade). Desde que o enredo (mŷthos) seja dotado de unidade de ação, dispondo certos caracteres $(\bar{e} t h \bar{e})$ que agem de modo a sofrer certas mudanças segundo a verossimilhança ou a necessidade, o que acontece de acordo com o pensamento (diánoia) (quando dizem o que é pertinente e adequado), valendo-se de uma determinada elocução (léxis), a tragédia terá seu efeito básico garantido, para isso não sendo necessário sequer recorrer aos ornamentos musicais e corais (melopoiía) ou aos efeitos visuais do espetáculo cênico (ópsis) (Poet. 6.1450a15-1450b19).

De que modo a teoria aristotélica sobre a origem da poesia e do drama está ligada a esse entendimento? Propondo que os seres humanos praticam a poesia inicialmente por uma tendência natural à mímēsis, ao ritmo e à harmonia, Aristóteles supõe que, a partir de motivos improvisados, surgiram certos gêneros poéticos ligados aos caracteres desses primeiros poetas: dentre os elevados, hinos e encômios; dentre os baixos, invectivas. Com Homero surgiram outros gêneros: as epopeias (elevadas) e os poemas iâmbicos (baixos). Esses gêneros poéticos, contudo, tornaram-se obsoletos quando surgiram as tragédias e as comédias - estas, a partir dos cantos fálicos, enquanto aquelas, a partir dos ditirambos. Para Aristóteles, a tragédia destaca-se de todos os gêneros miméticos no que tange "ao exercício efetivo da arte poética [tồi tềs tékhnēs érgōi]" (Poet. 26.1462b12), por isso desenvolve uma teoria mais elaborada sobre suas origens, na qual os paralelismos são notáveis: partindo do gênero coral do ditirambo, associado à dança, dotado de caráter satírico, com histórias breves, elocução ridícula e tendo por metro o tetrâmetro trocaico, suas performances foram se desfazendo pouco a pouco da preponderância do elemento coral e coreográfico, desenvolvendo um caráter sério, mais associado ao diálogo, com histórias de certo tamanho, linguagem ornamentada e tendo por metro, nas partes dialogadas, o iambo. Nesse mesmo sentido, Aristóteles sugere que o exarconte do ditirambo se transformou no ator da tragédia, passando a contracenar na sequência com um segundo ator e depois com um terceiro, de modo a fazer com que o diálogo (lógos) se tornasse o verdadeiro 
protagonista desse gênero mimético. ${ }^{13}$ Mas a consequência dessa diferenciação e multiplicação gradual dos atores a partir do exarconte ultrapassou em muito o mero favorecimento do diálogo, pois instituiu a possibilidade de que as próprias ações pudessem ser encenadas (em detrimento de elementos melopaicos e espetaculares, como a dança e o canto do coro ditirâmbico). Ou seja, oferecendo mais espaço para "a trama das ações [hē tồn pragmátōn sýstasis]" (Poet. 6.1450a15) - i.e., para o enredo (mŷthos) -, a tragédia veio a desenvolver aquilo que definiria sua essência e que lhe permitiria cumprir seu verdadeiro efeito, em detrimento justamente daqueles elementos que se revelavam os menos importantes para Aristóteles: melopeia e espetáculo. Tal como proposto por Depew (2007, p. 141), o desenvolvimento gradual do ditirambo configura-se como o único modo de se gerar uma tragédia completamente formada e efetiva, segundo a definição da essência que a Poética oferece dela.

A teoria das origens da poesia e do drama está profundamente implicada na compreensão que Aristóteles apresenta sobre a arte poética. Nesse sentido, o filósofo revela-se um herdeiro autêntico das mais fundamentais intuições de seu mestre, Platão: ciente de que o princípio é o primeiro termo a partir do qual algo é, ou é gerado, ou é conhecido, ${ }^{14}$ Aristóteles determina as origens da poesia e do drama a fim de afirmar o que cada um deles é, o que cada um deles veio a ser e o que pode ser conhecido acerca de cada um deles. $\mathrm{O}$ desdobramento investigativo dessas intuições forma o complexo texto da Poética.

${ }^{13}$ Levando em conta a importância do diálogo para o desenvolvimento da filosofia de Platão, não seria descabido defender - seguindo aquilo que Peter Szondi e Roberto Machado já haviam sugerido sobre a importância da tragédia para o desenvolvimento da "filosofia do trágico" no séc. XIX - que a tragédia também teria sido fundamental para o desenvolvimento da dialética socrático-platônica e da própria forma assumida por essa filosofia. Nesse sentido, o platonismo poderia ser visto como uma das primeiras manifestações de "filosofia do trágico".

${ }^{14}$ A alusão aqui é ao início do livro delta da Metafisica. Depois de elencar seis diferentes definições para arkhé - dentre as quais seria possível sugerir como tradução em português, no mínimo, "princípio", "início", "propedêutica", "origem", "fundamento", "causa", "poder" e "premissa" -, Aristóteles propõe o seguinte: "Então é comum a todas as definições de arkhế ser o primeiro ponto a partir do qual algo é, ou se torna, ou é conhecido." (Arist. Met. 1013a17). 


\section{Referências}

ARISTÓTELES. Poética. Ed. bilíngue; tradução, introdução e notas de Paulo Pinheiro. São Paulo: Editora 34, 2015.

DEPEW, D. From Hymn to Tragedy: Aristotle's Genealogy of Poetic Kinds. In: CSAPO, E.; MILLER, M. The Origins of Theater in Ancient Greece and Beyond: From Ritual to Drama. Cambridge: Cambridge University Press, 2007. p. 126-49.

DUPONT-ROC, R.; LALLOT, J. Introduction (Poétique). In: ARISTOTE. Poétique. Traduction et notes de Roselyne Dupont-Roc e Jean Lallot. Paris: Éditions du Seuil, 1980a. p. 9-29.

DUPONT-ROC, R.; LALLOT, J. Notes (Poétique). In: ARISTOTE. Poétique. Traduction et notes de Roselyne Dupont-Roc e Jean Lallot. Paris: Éditions du Seuil, 1980b. p. 143-416.

HALLIWELL, S. Plato and Aristotle on the Denial of Tragedy. Proceedings of the Cambridge Philological Society, Cambridge v. 30, p. 49-71, 1984.

HALLIWELL, S. Aristotle's Poetics. In: KENNEDY, G. (Ed.): The Cambridge History of Literary Criticism: Classical Criticism. Cambridge: Cambridge University Press, 1989. v. 1. p. 149-183.

HEGEL, G. W. F. Linhas fundamentais da filosofia do direito ou Direito natural e ciência do estado em compêndio. Tradução de Paulo Meneses et al. São Leopoldo, RS: UNISINOS, 2010 [1967].

KAHN, C. Plato and the Socratic Dialogue: The Philosophical Use of a Literary Form. Cambridge: Cambridge University Press, 1996.

MACHADO, R. O nascimento do trágico: de Schiller a Nietzsche. Rio de Janeiro: Jorge Zahar, 2006.

NUSSBAUM, M. The Fragility of Goodness: Luck and Ethics in Greek Tragedy and Philosophy. Revised Ed. Cambridge: Cambridge University Press, 2001 [1986].

PLATO. Platonis Opera. Edited by John Burnet. Oxford: Oxford University Press, 1903. 
SILVA, R. A ordem do discurso na Atenas Clássica. CONGRESSO INTERNACIONAL DA ABRALIC, 15., Rio de Janeiro, 07-11 ago. 2017. Anais eletrônicos... v. 2. Rio de Janeiro: UERJ, 2017. p. 26842694. Disponível em: <http://abralic.org.br/downloads/2017_anais ABRALIC_vol_2.pdf $>$. Acesso em: 06 set. 2018.

SZONDI, P. Ensaio sobre o trágico. Tradução de Pedro Süssekind. Rio de Janeiro: Jorge Zahar, 2004.

VELOSO, C. Il problema dell'imitare in Aristotele. Quaderni Urbinati di Cultura Classica, Roma, v. 65, n. 2, p. 63-97, 2000.

VELOSO, C. Depurando as interpretações da kátharsis na Poética de Aristóteles. Síntese - Revista de Filosofia, Belo Horizonte, v. 31, n. 99, p. 13-25, 2004.

Recebido em: 20 de setembro de 2018. Aprovado em: 5 de dezembro de 2018. 